\title{
Identification of electroactive sites in Prussian Yellow films
}

\author{
J. Agrisuelas ${ }^{1}$, J.J. García-Jareño ${ }^{1, *}$, C. Moreno-Guerrero ${ }^{1}$, A. Roig ${ }^{2}$, F. Vicente ${ }^{1}$ \\ ${ }^{1}$ Departament de Química Física, Universitat de València. C/ Dr. Moliner, 50, 46100, \\ Burjassot, València, Spain. \\ ${ }^{2}$ Departament de Química Física i Analítica, Universitat Jaume I, Av. de Vicent Sos \\ Baynat, s/n. 12071 Castelló de la Plana, Spain.
}

* Email corresponding author: Jose.J.Garcia@uv.es

This work has been presented by F. Vicente at the $9^{\text {th }}$ International Symposium on Electrochemical Micro \& Nanosystem Technologies (EMNT), Linz (Austria), 2012.

\begin{abstract}
.
Prussian Blue films were electrogenerated on the surface of the transparent ITO electrodes. The electrochemical oxidation to the Prussian Yellow form was investigated by means of in situ voltammetry and Vis-NIR spectroscopic techniques. Changes of the whole spectra between 400 and $950 \mathrm{~nm}$ were analyzed and three characteristic wavelengths were selected to in situ follow the electrochemical changes of the films. Voltammetric peaks and absorbance derivative curves at these three wavelengths were deconvoluted and were interpreted such as the overlapping of different electrochemical processes. The correlation between these overlapped processes has allowed proposing three different electrochemical processes for the interpretation of the whole electrochemical response. One of these processes corresponds to the oxidation of $\mathrm{Fe}_{\text {low spin }}^{2+}-\mathrm{CN}-\mathrm{Fe}_{\text {high spin }}^{3+}$ units where the electrical charge is balanced by the exchange of neighbor potassium cations. The second one is associated to the oxidation of $F e_{\text {low spin }}^{3+}-C N-F e_{\text {high spin }}^{2+}$ trapped sites and the third one also to the oxidation of $F e_{\text {low spin }}^{2+}-C N-F e_{\text {high spin }}^{3+}$ units but in this last case, the absence of neighbor potassium cations causes that the electrical charge balance takes place by the exchange of some anions such as the chloride. These processes have been identified on the basis of previous results and on the interesting information provided by the coupling voltammetry and absorbance derivative curves at these characteristic wavelengths.
\end{abstract}




\section{Introduction.}

Prussian Blue (ferric ferrocyanide, PB) is a well-known mixed valence hexacyanoferrate compound which has attracted recent interest due to some interesting properties if deposited as a thin film on the surface of different electrode substrate. Among others, electrochromic and magnetic properties, their possible use as a biosensor or their electrocatalytic behavior are of special interest [1-9].

Chemically deposited Prussian blue films have been reported the first in 1978 by V.D. Neff on the surface of gold electrodes [10]. Some years later, in 1982 Itaya et al. [3,11-14] described a galvanostatic procedure to produce good and controlled quality PB films on different type of electrode substrate. In these works, it has been proved that some electrochemical properties are dependent on the rate of electrogeneration, obtaining narrower and sharper voltammetric peaks for the higher current deposited PB films. These PB films were galvanostatically generated from $\mathrm{FeCl}_{3}$ and $\mathrm{K}_{3} \mathrm{Fe}(\mathrm{CN})_{6}$ acid solutions. During the electrodeposition process, ferricyanide anions reduce to ferrocyanide anions and the potassium free insoluble Prussian Blue films (i-PB) are generated in the mixed valence form $\left(\mathrm{Fe}_{4}^{3+}\left(\mathrm{Fe}^{2+}(\mathrm{CN})_{6}\right)_{3} \cdot \mathrm{mH}_{2} \mathrm{O}, \mathrm{Fe}^{3+} / \mathrm{Fe}^{2+}\right)$.

The crystal structure of these i-PB films has been reported to be cubic face centered [15-22] with space group symmetry $\boldsymbol{F m 3 m}$. i-PB films present structural vacancies, 1/4 of the ferrocyanide sites. Thus, there are at least two different $\mathrm{Fe}^{3+}$ sites in the $\mathrm{PB}$ structure, one of them hexacoordinated with -NC and the other, near the ferrocyanide vacancies, tetracoordinated with -NC groups plus two ligands which may be hydroxide anions or water molecules depending on the $\mathrm{pH}[23,24]$. These vacancies have been identified to be responsible for some of the electrochemical, electrochromic or magnetic properties of these films and it proves essential to understand the electrochemical processes taking place in these vacancies $[23,24]$. These i-PB films may be reduced to the colorless form known as Everitt's Salt (ES) ( $\left.\mathrm{K}_{4} \mathrm{Fe}_{4}^{2+}\left(\mathrm{Fe}^{2+} \mathrm{CN}_{6}\right)_{3} \cdot \mathrm{mH}_{2} \mathrm{O}, \mathrm{Fe}^{2+} / \mathrm{Fe}^{2+}\right)$. This process may be described by this equation: 


$$
\mathrm{Fe}_{4}^{3+}\left(\mathrm{Fe}^{2+} \mathrm{CN}_{6}\right)_{3} \cdot \mathrm{xH}_{2} \mathrm{O}+4 \mathrm{~K}^{+}+4 e^{-} \square \quad \mathrm{K}_{4} \mathrm{Fe}_{4}^{2+}\left(\mathrm{Fe}^{2+} \mathrm{CN}_{6}\right)_{3} \cdot \mathrm{xH}_{2} \mathrm{O}
$$

i-PB Prussian Blue Everitt's Salt (ES, colorless)

There is also the possibility of i-PB films to be oxidized to the yellow form (PY, $\mathrm{Fe}^{3+} / \mathrm{Fe}^{3+}$ ), but PY films generated this way proved very unstable and the films disappear after a few cycles since there are no free cations within the film to balance electrical charge during the oxidation process, and thus, electrical charge is compensated by expelling $\mathrm{Fe}^{3+}$ ions, and the collapse of the structure takes place[25,26]. It is also possible that chloride anions enter the PB film during the oxidation process to balance electrical charge and to form the $\mathrm{Fe}_{4}^{3+}\left(\mathrm{Fe}^{3+} \mathrm{CN}_{6}\right)_{3} \mathrm{Cl}_{3} \cdot \mathrm{mH}_{2} \mathrm{O}$ structure, but this process seems to not take place to a great extent $[27,28]$.

As commented before, the structure of i-PB films freshly deposited following the procedure described by Itaya et al. corresponds to the mixed valence formula $\mathrm{Fe}_{4}^{3+}\left(\mathrm{Fe}^{2+}(\mathrm{CN})_{6}\right)_{3} \cdot \mathrm{mH}_{2} \mathrm{O}$. This structure undergoes into the soluble $\mathrm{PB}$ (s-PB) by voltammetric cycling i-PB films around the $P B \square$ ES system[1,25,29]. The soluble structure was characterized by the presence of some potassium cations within the PB structure. This s-PB has been described in the literature as $\mathrm{KFe}^{3+} \mathrm{Fe}^{2+}(\mathrm{CN})_{6} \cdot \mathrm{mH}_{2} \mathrm{O}$ and voltammograms present narrower and taller peaks in acidic $\mathrm{KCl}$ solutions[1,16,22,30,31].

It is also known the presence of a macro zeolitic structure with $3.2 \AA$ diameter channels by where only cations with the appropriate size can move (potassium, ammonium, cesium, hydronium). It has been corroborated that PB films deposited at higher currents present a more amorphous macro structure allowing the transport of larger hydrated cations such as sodium[12,32].

These s-PB films can be reversibly reduced to the colorless form (ES) and now, it is also possible to reversibly oxidize to the PY form since the electrical charge may be balanced by expelling potassium cations from within[12,25,26]. These electrochemical reactions of $\mathrm{PB}$ films in acidic $\mathrm{KCl}$ aqueous solutions have been described in the literature by some simplified reactions which evidently imply the exchange of charged species in order to keep the films electroneutrality: 


$$
\begin{gathered}
\mathrm{KFe}^{3+} \mathrm{Fe}^{2+}(\mathrm{CN})_{6} \cdot \mathrm{mH}_{2} \mathrm{O}+\mathrm{K}^{+}+e^{-} \square \quad \mathrm{K}_{2} \mathrm{Fe}^{2+} \mathrm{Fe}^{2+}(\mathrm{CN})_{6} \cdot \mathrm{mH}_{2} \mathrm{O} \\
\text { s-PB (Blue) } \\
\text { s-ES(colorless) }
\end{gathered}
$$

$$
\begin{array}{cc}
\mathrm{KFe}^{3+} \mathrm{Fe}^{2+}(\mathrm{CN})_{6} \cdot \mathrm{mH}_{2} \mathrm{O} \square & \mathrm{Fe}^{3+} \mathrm{Fe}^{3+}(\mathrm{CN})_{6} \cdot \mathrm{mH}_{2} \mathrm{O}+\mathrm{K}^{+}+e^{-} \\
\text {s-PB (Blue) } & \text { s-PY(yellow) }
\end{array}
$$

Experimental results for these processes clearly proved that the electrical charge enclosed within the voltammetric peak associated to the $P B \square P Y$ process is about $60 \%$ of the electrical charge enclosed in the voltammetric peak corresponding to the $P B \square E S$ process[33]. However, according to this structure and to equations (2) and (3) there is no convincing explanation for this different electrical charge, since there are the same number of $\mathrm{Fe}^{3+}$ centers to be reduced during the $P B \square \quad E S$ process than $\mathrm{Fe}^{2+}$ to be oxidized during the $P B \square \quad P Y$ process.

As seen before, redox processes of PB films are always accompanied by color changes and mass changes (ion exchange). Blue color of this material is explained by electron transfer between low/high spin iron sites in $\mathrm{Fe}_{\text {low spin }}^{2+}-\mathrm{CN}-\mathrm{Fe}_{\text {high spin }}^{3+}$ repetitive units [34]. However, in the mixed valence form, PB form, not all low spin iron sites correspond to $\mathrm{Fe}^{2+}$. There is a part of trapped sites where the low/high spin sites are inverted. These centers $F e_{\text {low spin }}^{3+}-C N-F e_{\text {high spin }}^{2+}$ present an absorption band at wavelengths near $380 \mathrm{~nm}$ [34]. The derivative of the voltabsommetric scans, together with previous nano-electrogravimetric and X-ray diffraction results, allow different electrochemical processes to be distinguished during the Prussian blue (PB) voltammetric scan. Thus, during the $P B \square E S$ process it is known that potassium, proton, and hydrated proton counterions are related here to the electrochemical reactions of specific $\mathrm{Fe}$ sites. Potassium counterions show two different sites for their insertion: one located in the crystalline framework and another in ferrocyanide vacancies. From the monitoring of electroactive Fe sites, the covalent-exchange model is suggested as one of the first approaches to explain the origin of the PB magnetic ordering observed at room temperature during voltammetric scanning[34]. Another band is detected at the 
near infrared at wavelengths close to $900-1000 \mathrm{~nm}$ which may be attributed to a forbidden transition associated to the $690 \mathrm{~nm}$ one but also to other optically active centers [23].

As commented above, one of the most interesting properties of these materials is their ability to change from the blue color for the mixed valence form $\left(\mathrm{Fe}^{3+} / \mathrm{Fe}^{2+}\right.$ Prussian Blue) to the reduced colorless form ( $\mathrm{Fe}^{2+} / \mathrm{Fe}^{2+}$ Everitt's Salt), but also to the oxidized yellow form ( $\mathrm{Fe}^{3+} / \mathrm{Fe}^{3+}$, Prussian Yellow). Thus the oxidation of the mixed valence form to the fully oxidized form causes both, the decrease of the $690 \mathrm{~nm}$ absorption band and the increase of a new characteristic absorption band associated to the yellow color at wavelengths near $430 \mathrm{~nm}$. These color changes are eye-observable, but it proves more interesting to quantify them by means of the Lambert-Beer's law and to obtain information on the amount of active centers that may be reduced or oxidized. This is possible if absorbance changes are related with the electrical current passed during an electrochemical experiment, i.e. a voltammetric scan[35]. For the most simple case, where the electrical current $(i=d q / d t)$ is due only to one electroactive process and that all the absorbance change at a characteristic wavelength is only due to the variation of the number of sites associated to this electroactive process $(n)$ :

$$
\begin{aligned}
& \frac{d A^{\lambda}}{d t}=\frac{d\left(\varepsilon^{\lambda} \cdot l \cdot c\right)}{d t}=\varepsilon^{\lambda} \frac{d \Gamma}{d t}=\frac{\varepsilon^{\lambda}}{S} \frac{d n}{d t}=\varepsilon^{\prime \lambda} \frac{d n}{d t} \\
& i=\frac{d q}{d t}=z F \frac{d n}{d t} \\
& F \frac{d A^{\lambda} / d t}{i}=F \frac{d A^{\lambda} / d t}{d q / d t}=F \frac{d A^{\lambda}}{d q}=\frac{\varepsilon^{\prime \lambda}}{z}
\end{aligned}
$$

In these equations, $n$ refers to the number of active sites, $\Gamma$ refers to an apparent surface concentration of electroactive sites, $l$ refers to the length of the light path, $S$ the surface area of the electrode and $c$ the volume concentration of active sites. $A^{\lambda}$ represents the absorbance at a characteristic $\lambda$ wavelength, $z$ the number of electrons involved per active center in the electrochemical process and $q$ the electrical charge.

For the case of only one electro-optically active species, $F d A^{\lambda} / d q$ is a direct measurement of the electrochromic efficiency of the polymer at this wavelength, $\varepsilon^{\prime \lambda}$, 
In the case of voltammetric peaks due to more than one electrochemical proces, the information provided by electro optical signals may be useful to separate the whole response into individual responses[23,24,34,35]. The possibilities of this analysis strongly increase by the use of crossed signals such as $F d A^{\lambda} / d q$. This analysis requires the in situ measurement of both, electrical and optical signals. In a recent paper, the $P B \square \quad P Y$ process was analyzed by means of EQCM+CV experiment in a $\mathrm{KNO}_{3}$ solution[28]. These studies have been performed on the surface of gold electrodes. The solution media was $\mathrm{KNO}_{3}$ instead of $\mathrm{KCl}$ solutions since chloride anions can oxidize gold electrodes at potentials where $P B \square \quad P Y$ process takes place. Thus, electro-optical changes associated to this process cannot be studied on gold electrodes in $\mathrm{KCl}$ solutions. For this purpose the transparent ITO (indium-tin oxide) electrode is a better choice which proved both, good optical properties in the range of wavelengths studied and a very stable response at very anodic potentials in $\mathrm{KCl}$ solutions[25,33,36,37]. However, this electrode presents an intrinsic electrical resistance that causes unsymmetrical broadening of the voltammetric peaks [38]. This undesirable effect may be partially corrected if ohmic drop compensation is activated on the potentiostat control software $[39,40]$.

The aim of this work is to study the electrochemical processes associated to the oxidation of Prussian Blue films to the Prussian Yellow form by following the spectroelectrochemical responses at different characteristic wavelengths and to identify the different contributions to the whole response in these experiments.

\section{Experimental}

All chemicals used were Scharlau ${ }^{\mathrm{TM}}$ Analytical Reagent quality. Prussian Blue films were deposited on the surface of $1 \times 1 \mathrm{~cm}$ ITO (Galsstron, $30 \Omega / \square$ ) electrodes. Prussian Blue was deposited from $0.02 \mathrm{M} \mathrm{K}_{3} \mathrm{Fe}(\mathrm{CN})_{6}, 0.02 \mathrm{M} \mathrm{FeCl}_{3}$ and $0.01 \mathrm{M} \mathrm{HCl}$ freshly prepared solutions by applying a controlled cathodic current density of $40 \mu \mathrm{A}$ $\mathrm{cm}^{-2}$ during $150 \mathrm{~s}$. The film thickness was estimated about $115 \mathrm{~nm}[38,41]$.

PB films freshly prepared (i-PB) were stabilized and converted into the soluble form (s-PB) by means of cyclic voltammetry around the PB $\square$ ES system in a $0.5 \mathrm{M}$ $\mathrm{KCl}, \mathrm{pH}=3.0$ solution until narrow and sharp peaks appear $(15$ cycles between $0.6 \mathrm{~V}$ and $-0.2 \mathrm{~V}$ at $0.02 \mathrm{~V} \mathrm{~s}^{-1}$ scan rate)[25]. Voltammetric experiments were carried out in a 
typical three electrodes cell, where the reference was the $\mathrm{Ag} / \mathrm{AgCl} / \mathrm{KCl}$ (sat) electrode, the counter electrode a Pt mesh and the working electrode was the ITO/PB electrode. For practical purposes, all potentials were referred to the $\mathrm{Ag} / \mathrm{AgCl} / \mathrm{KCl}$ (sat) electrode (0.197 V against the SHE at 298.15 K).

For the study of the $P B \square \quad P Y$ process, voltammetric experiments were carried out at the scan rate of $5 \mathrm{mVs}^{-1}$ in the potential range from $+1.2 \mathrm{~V}$ to $-0.2 \mathrm{~V}$ against the $\mathrm{Ag} / \mathrm{AgCl} / \mathrm{KCl}$ (sat) starting at $0.6 \mathrm{~V}$ and in the cathodic sense $(0.6 \mathrm{~V} \rightarrow$ $0.2 \mathrm{~V} \rightarrow 1.2 \mathrm{~V} \rightarrow 0.6 \mathrm{~V})$.

All experiments were carried out in $\mathrm{KCl} 0.5 \mathrm{M}, \mathrm{pH}=3.0$ solutions and at the controlled temperature of $25^{\circ} \mathrm{C}$.

Ac-electrogravimetry results were obtained from PB films deposited on the gold electrode of quartz-crystal microbalance. $\mathrm{PB}$ films were stabilized in the same $\mathrm{KCl}$ solutions than those used for the ITO/PB study. After that, these films were studied at $0.850 \mathrm{~V}$ and $0.975 \mathrm{~V}$ against the $\mathrm{Ag} / \mathrm{AgCl} / \mathrm{KCl}$ (sat) reference electrode and in $0.5 \mathrm{M}$ $\mathrm{KNO}_{3}$ and $\mathrm{pH}=3.0$ solutions. For more experimental details concerning the acelectrogravimetry experiment see $[23,42]$.

The potentiostat was an AUTOLAB PGSTAT 30 and the color response was processed by means of a diode-array spectrometer Stellarnet ${ }^{\mathrm{TM}}$ allowing the whole spectra $(400-1000 \mathrm{~nm})$ to be recorded each $0.2 \mathrm{~s}$. Spectra were recorded as number of counts at each wavelength which is directly converted into light intensity at a given wavelength, $I^{\lambda}$. In this work, it is preferred to convert into an apparent absorbance derivative at a specific wavelength $\left(A^{\lambda}\right)$ by means of:

$$
\begin{aligned}
& A^{\lambda}=-\log \left(I^{\lambda} / I_{0}^{\lambda}\right)=-\log \left(I^{\lambda}\right)+\log \left(I_{0}^{\lambda}\right) \\
& \frac{d A^{\lambda}}{d t}=\frac{d\left(-\log \left(I^{\lambda}\right)+\log \left(I_{0}^{\lambda}\right)\right)}{d t}=-\frac{d\left(\ln \left(I^{\lambda}\right)\right)}{\ln (10) \cdot d t}=\frac{1}{2.303 I^{\lambda}} \frac{d I^{\lambda}}{d t}
\end{aligned}
$$


Since, $I^{\lambda}$, intensity of transmitted light, is proportional to the number of counts ( $n_{\text {counts }}^{\lambda}$ ) received by the diode at this wavelength, then we can write:

$$
\frac{d A^{\lambda}}{d t}=\frac{1}{2.303 I^{\lambda}} \frac{d I^{\lambda}}{d t}=\frac{1}{2.303 n_{\text {counts }}^{\lambda}} \frac{d n_{\text {counts }}^{\lambda}}{d t}=\frac{1}{2.303} \frac{d\left(\ln \left(n_{\text {counts }}^{\lambda}\right)\right)}{d t}
$$

\section{RESULTS AND DISCUSSION.}

Redox processes of PB films are accompanied by color changes. Electrical current associated to these redox processes is recorded together with the Visible-Near infrared (Vis-NIR) spectra during voltammetric experiments of s-PB films (Figure 1). Two main voltammetric peaks are observed, centered at $0.22 \mathrm{~V}$ and at $0.95 \mathrm{~V}$, respectively. Associated to both voltammetric peaks, changes of absorbance derivative at $690 \mathrm{~nm}$ are well observed as mountains or valleys. During the oxidation process $E S \rightarrow P B$, absorbance increases at this wavelength (mountain) and during the oxidation $P B \rightarrow P Y$, this blue color disappears and absorbance at $690 \mathrm{~nm}$ decreases (valley). Maximum changes of absorbance $\left(d A^{690} / d t\right)$ are in apparently good agreement with these voltammetric peaks. Besides, there is another well observed color change, it is the appearance of a characteristic yellow color for the fully oxidized form. Figure 1 also shows a mountain at $420 \mathrm{~nm}$ associated to this color change and centered at the $0.95 \mathrm{~V}$ potential which corresponds to the $P B \square \quad P Y$ voltammetric peak.

Since now, we have described the more evident color changes taking place during the electrochemical processes. However, there are also other spectroelectrochemical changes to be analyzed. A more detailed interpretation of Figure 1 can be due. We consider also the absorption band at wavelengths near $900 \mathrm{~nm}$ that causes an apparent non-symmetry of the $690 \mathrm{~nm}$ mountain or valley. Thus, and as a first approach we confirm 2 characteristic wavelengths proposed by Robin [43] and also a new characteristic wavelength associated to the yellow form.

The information provided by Figure 1 is very useful, since it allows detecting the most important wavelengths where absorbance changes during redox processes. However, in order to obtain quantitative information it is preferred to plot derivative 
$d A^{\lambda} / d t$ curves together with the current measured curves. Figure 2 represents this dependence on the applied potential at these three characteristic wavelengths.

The first observation should be that in the potential range [0.45,0.75] $\mathrm{V}$ there is no important color change at these wavelengths, corroborating that color changes are always associated to redox processes. Looking at the $P B \square E S$ process one can find the good correlation between voltammetric and $d A^{690} / d t$ peaks. However, the current of shoulders of the voltammetric peak should be preferably associated to changes of absorbance at other wavelengths. This behavior has been previously explained on the basis of different iron sites in the PB structure and their role during the $P B \quad \square \quad E S$ process [23].

Looking at the oxidation $P B \square \quad P Y$ process which takes place at potentials in the range $[0.75,1.10] \mathrm{V}$ one can observe that the size of this voltammetric peak proves clearly smaller than the peak corresponding to the $P B \square \quad E S$ process indicating that a small amount of $\mathrm{Fe}^{2+}$ sites are oxidized to the PY form. However, the absorbance changes associated to the $690 \mathrm{~nm}$ and to the $430 \mathrm{~nm}$ bands are good correlated with the voltammetric peak. Obviously, $d A^{690} / d t$ and $d A^{430} / d t$ have opposite sign in this potential range since the oxidation $P B \rightarrow P Y$ causes the disappearance of the blue color, but the appearance of the yellow color. At more positive potentials than the peak potential, it appears also a shoulder during both, the anodic and the cathodic scan. Electrocatalytic activity of PB films at these potentials $(0.95-1.10 \mathrm{~V}$ against the $\mathrm{Ag} / \mathrm{AgCl} / \mathrm{KCl}(\mathrm{sat})$ ) and in this acidic solution has not been reported. Thus, it seems that this shoulder is not mainly caused by oxygen evolution. Besides, as commented above, this shoulder also appears during the cathodic scan. If only associated to the oxygen evolution, thus the oxygen produced during the anodic scan should be adsorbed on the PB film and after, reduced again and this explanation seems unlikely. The $d A^{900} / d t$ band appears at these potentials, decreasing during the anodic scan and increasing during the cathodic one. At these potentials there are also changes of absorbance at 430 and $690 \mathrm{~nm}$, and thus these changes in absorbance may be attributed to electrochemical changes in Prussian blue films seeming a more probable explanation for this shoulder.

In those concerning changes of absorbance at $900 \mathrm{~nm}$, it should be noted that in recent papers, these changes have been associated to electrochemical processes of $\mathrm{Fe}$ 
sites near the $\mathrm{PB}$ vacancies structureduring the $P B \square \quad E S$ process. In this case, it is not probable, since these centers have been oxidized at potentials near the PB form, thus these absorbance changes should be attributed to other electrochemical processes. Anyway, from these experimental results we can say that we need more than one process to explain both, the voltammetric peak shape and the absorbance derivative curves.

The simplest model used to interpret voltammetric waves of films is that based on the adsorption of both, the reduced and the oxidized forms of the electroactive film [44]. If we assume also that the electroactive process takes place faster enough to consider that the Nernst equation applies any time at the electrode surface, thus we can obtain an analytical expression describing the relationship between electrical current and the applied potential. First we can consider that the electrical current, mass changes and absorbance changes are directly related with the change of the number of electroactive sites, in this case for the oxidation process $P B \square \quad P Y$ it corresponds with the number of $\mathrm{Fe}^{2+}$ sites in the PB structure. Then, we can write for the $d q / d t$ (current), $d m / d t$ and $d A^{\lambda} / d t$ :

$$
\begin{aligned}
& \frac{d q}{d t}=\sum_{i=1}^{N} F\left(\frac{d n_{F e^{2+}}}{d t}\right)_{i} \\
& \frac{d m}{d t}=\sum_{i=1}^{N} \gamma_{i} M_{i}\left(\frac{d n_{F e^{2+}}}{d t}\right)_{i} \\
& \frac{d A^{\lambda}}{d t}=\sum_{i=1}^{N} \zeta_{i}^{\lambda}\left(\frac{d n_{F e^{2+}}}{d t}\right)_{i}
\end{aligned}
$$

In these expressions, $\zeta_{i}^{\lambda}$ represents the apparent electrochromic efficiency for the $\mathrm{i}^{\text {th }}$ process, $\gamma_{i} M_{i}$ the molar mass of the exchanged species during the $i^{\text {th }}$ electrochemical process, positive for anions and negative for cations and F the Faraday's constant. 
Assuming also that the total number of $F e$ sites keeps constant during the voltammetric experiment and that there is no interaction between neighboring active sites we can obtain an equation describing the dependence of the number of $\mathrm{Fe}^{2+}$ sites on the applied potential during a voltammetric experiment[23,44,45].

$$
\begin{aligned}
& \left(\frac{d n_{F e^{2+}}}{d E}\right)_{i}=\frac{C_{i}}{\cosh ^{2}\left(b_{i} \cdot\left(E-E_{i}^{0}\right)\right)} \\
& \left(d n_{F e^{2+}}\right)_{i}=\frac{C_{i}}{\cosh ^{2}\left(b_{i} \cdot\left(E-E_{i}^{0^{\prime}}\right)\right)} d E \\
& \left(n_{F e^{2+}}\right)_{\max , i}=\int_{-\infty}^{+\infty}\left(d n_{F e(I I)}\right)_{i}=\frac{2 C_{i}}{b_{i}} \text { where } C_{i}=\frac{b_{i}\left(n_{F^{2+}}\right)_{\text {max }, i}}{2} \\
& \left(\frac{d n_{F e^{2+}}}{d E}\right)_{i}=\left(\frac{d n_{F e^{2+}}}{d t} \frac{d t}{d E}\right)_{i}=\left(\frac{d n_{F e^{2+}}}{d t} \frac{1}{v}\right)_{i} \\
& \left(\frac{d n_{F e^{2+}}}{d t}\right)_{i}=\frac{v b_{i}\left(n_{F e^{2+}}\right)_{\max , i}}{2 \cosh ^{2}\left(b_{i} \cdot\left(E-E_{i}^{0^{\prime}}\right)\right)}
\end{aligned}
$$

In these expressions, $v$ represents the scan rate of the voltammetric experiment, $C_{i}$ is a constant related with the maximum number of active $F e^{2+}$ sites and $b_{i}=\frac{\alpha_{i} F}{R T}$ where $\alpha_{i}$ represents the symmetry factor.

Accordingly with these expressions we can try to simulate the experimental shape of voltammetric and $d A^{\lambda} / d t$ curves at 430, 690 and $900 \mathrm{~nm}$ by considering two parallel electrochemical processes in each one of the studied cases. The main of these processes should be centered at potentials near $0.900 \mathrm{~V}$ against the $\mathrm{Ag} / \mathrm{AgCl} / \mathrm{KCl}$ (sat) 
reference electrode and the second one at potentials between 0.950 and $1.000 \mathrm{~V}$ against the same reference electrode. Figures $3 \mathrm{a}$ and $3 \mathrm{~b}$ represents the experimental curves and the simulated ones for the voltammetric currents during the cathodic scan (3a) and the anodic scan (3b). Figures $4 \mathrm{a}$ and $4 \mathrm{~b}$ show the simulation obtained for the $d A^{430} / d t$ curves for the cathodic and anodic scans, respectively. Figures 5a and 5b correspond to the $d A^{690} / d t$ and Figures $6 \mathrm{a}$ and $6 \mathrm{~b}$ to the $d A^{900} / d t$ curves. Table 1 collects numerical values obtained from the fitting of these experimental curves to the model proposed by equations (10) and (17) for the current curves and equations (12) and (17) for the absorbance derivative curves.

Looking at these figures for the anodic scan, we can draw some quick conclusions. First, there is a good correlation between the voltammetric peak shape and the peak shape obtained from the functions $d A^{\lambda} / d t$ at 430 and $690 \mathrm{~nm}$ wavelengths. Secondly, the shape of all these experimental peaks can be described as the sum of two peaks in accordance with the equations (10) and (12). The potentials obtained for these peaks seem to coincide for voltammetric peak currents and $d A^{\lambda} / d t$ at 430 and $690 \mathrm{~nm}$ wavelengths. The larger peak is obtained in these cases at potentials near $0.9 \mathrm{~V}$, while the secondary peak is obtained at slightly higher potentials, near $0.98 \mathrm{~V}$. Values for $b$ parameters are similar in all the studied cases and the relation between $C$ values for the main and the secondary peaks are also very similar for current and $d A^{690} / d t$ curves. However, for the $d A^{430} / d t$ peak deconvolution this relationship clearly proves smaller indicating that the secondary process causes smaller changes of absorbance at this wavelength, or in other words, during the oxidation $P B \rightarrow P Y$ the characteristic blue color disappears at this potential, but the oxidized yellow form obtained at $0.98 \mathrm{~V}$ proved 'less' yellow. For the cathodic scan, this deconvolution procedure shows a similar behavior. A possible explanation may be found in the fact that at these potentials it has been proven by EQCM studies in $\mathrm{KNO}_{3}$ aqueous solutions that anions participate as counterions during redox processes [28]. Thus, we can attribute this second process to the oxidation of $\mathrm{Fe}_{\text {low spin }}^{2+}-\mathrm{CN}-\mathrm{Fe}_{\text {high spin }}^{3+}$ units, but the electrical charge balance takes place by the exchange of anions (chloride). This hypothesis may be corroborated by recent structural studies where the s-PB structure has been described accordingly with the formula $\mathrm{Fe}_{4}^{3+}\left[\mathrm{Fe}^{2+}(\mathrm{CN})_{6}\right]_{3} \cdot\left[\mathrm{K}_{2}^{+} \cdot \mathrm{OH}_{2}^{-} \cdot\left(\mathrm{mH}_{2} \mathrm{O}\right)\right]$. This structure implies that there 
are only 2 potassium cations within the s-PB structure by each $3 \mathrm{Fe}^{2+}(\mathrm{CN})_{6}^{4-}$ sites. Thus, 2/3 of these ferrocyanide sites may be oxidized to ferricyanide by expelling potassium cations but $1 / 3$ of these sites may only be oxidized by the participation of other counterion species, i.e. chloride anions. This structure also explains why voltammetric peaks for the $P B \square \quad P Y$ process prove smaller than those for the $P B \square \quad E S$ process. First, we have only $3 \mathrm{Fe}^{2+}(\mathrm{CN})_{6}^{4-}$ sites by each $4 \mathrm{Fe}^{3+}$ sites. This means that electrical charge for the $P B \square P Y$ process may be as maximum $3 / 4$ of the electrical charge enclosed in the voltammetric peak for the $P B \square E S$ process. Furthermore, if the participation of chloride anions is not very important, then as we have only 2 potassium cations by each $3 \mathrm{Fe}^{2+}(\mathrm{CN})_{6}^{4-}$ sites, the maximum electrical charge for the oxidation process should be only $\frac{2}{3} \times \frac{3}{4}=\frac{1}{2}$ of the total electrical charge enclosed in the voltammogram associated to the $P B \square \quad E S$ process. If the classical s-PB structure is considered $\left(\mathrm{KFe}^{3+} \mathrm{Fe}^{2+}(\mathrm{CN})_{6} \cdot \mathrm{mH}_{2} \mathrm{O}\right)$ then, electrical charges for the oxidation ( $P B \square \quad P Y$ ) and reduction ( $P B \square \quad E S$ ) processes should be identical which disagrees with the experimental evidence.

In order to confirm this hypothesis there is also the ratio $C_{2} / C_{1}$ concerning the $P B \square \quad P Y$ process in table 1 . This ratio may be interpreted as an estimation of the number of centers oxidized by the second process and the number of centers oxidized by the first process. Accordingly to this hypothesis, $\mathrm{C}_{2} / \mathrm{C}_{1}$ should reach a value near 0.50 (1/3 of the $F e_{\text {low spin }}^{2+}-C N-F e_{\text {high spin }}^{3+}$ oxidized by the participation of chloride anions and $2 / 3$ of the centers oxidized by the participation of potassium cations). Experimental results show values of 0.40 and 0.67 for the cathodic and the anodic peaks, respectively which are not very far from the expected 0.50 value. A similar behavior is obtained if the absorbance derivative deconvoluted curve at $690 \mathrm{~nm}$ wavelength is analyzed (0.41 and 0.60). At $430 \mathrm{~nm}$ smaller values for this ratio are reached, 0.25 and 0.31 for the cathodic and anodic peaks, respectively. A possible explanation for this result is that the presence of chloride anions near these sites makes that the electronic transition responsible for the yellow color of the oxidized form (430 $\mathrm{nm}$ ) to be more difficult and thus, the decrease of the molar absorptivity at this wavelength. 
As commented before, there is also another characteristic band centered at 900 $\mathrm{nm}$. Changes of absorbance at this wavelength take place at potentials slightly larger than those for the processes at $430 \mathrm{~nm}$ and at $690 \mathrm{~nm}$. These changes should also be interpreted as the overlapping of several (at least two) processes. Figures $5 \mathrm{a}$ and $5 \mathrm{~b}$ show these curves. One of them, the most important, is centered at potentials near 1.05 $\mathrm{V}$ and the smaller one at potentials between 0.97 and $0.98 \mathrm{~V}$. The coincidence of the potential of the smaller one with the secondary process of $d A^{690} / d t$ may be interpreted as the absorbance change at this wavelength $(900 \mathrm{~nm})$ and at this potential $(0.98 \mathrm{~V})$ may be attributed to the forbidden band associated to the electronic transition in $F e_{\text {low spin }}^{2+}-C N-F e_{\text {high spin }}^{3+}$ units [43].

The interpretation of the $1.05 \mathrm{~V}$ process proves not easy. At this potential there is also a current contribution, but the possible overlapping with the oxygen evolution makes not possible to obtain a clear response by the deconvolution procedure. This is not the case for the absorbance derivative curve at $900 \mathrm{~nm}$, where a well-defined peak is obtained; indicating that this absorbance change is not due to the oxygen evolution. One possible explanation is to attribute this process to the trapped ionic sites. It has been proposed that these trapped sites are responsible of the absorbance at $380 \mathrm{~nm}$ in s-PB films[24,34]. If s-PB films are reduced to the ES form, the absorbance decrease at 380 nm takes place when $\mathrm{Fe}^{3+}$ in these units is reduced to $\mathrm{Fe}^{2+}$. During the voltammetric reductions of s-PB films, this change takes place at more cathodic potentials than the main voltammetric peak potentials. At these same potentials it takes also place an important decrease of the absorbance at $900-1000 \mathrm{~nm}$. Thus, it has been proposed that these trapped sites are also responsible of the absorbance at NIR 900-1000 nm wavelengths[23] in s-PB films. In this study, makes it impossible to follow the $380 \mathrm{~nm}$ band since ITO is deposited on the surface of a glass electrode that absorbs at these wavelengths, but it proves easy to follow the $900 \mathrm{~nm}$ band. Therefore, we consider that these trapped sites $F e_{\text {low spin }}^{3+}-C N-F e_{\text {high spin }}^{2+}$ absorbs at $900 \mathrm{~nm}$, but this absorption

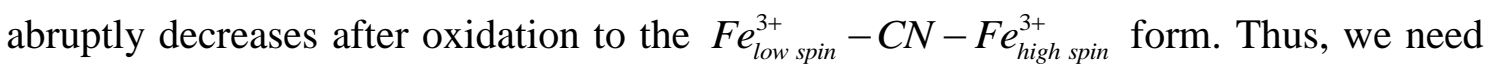
at least two electrochemical processes to interpret the $d A^{900} / d t$ curve during the $P B \square \quad P Y$ process:

$$
F e_{\text {low spin }}^{2+}-C N-F e_{\text {high spin }}^{3+} \square \quad F e_{\text {low spin }}^{3+}-C N-F e_{\text {high spin }}^{3+}
$$




$$
F e_{\text {low spin }}^{3+}-C N-F e_{\text {high spin }}^{2+} \square \quad F e_{\text {low spin }}^{3+}-C N-F e_{\text {high spin }}^{3+}
$$

On the other hand, the hypothesis on the partial participation of anions during the electrochemical process needs some extra experimental confirmation. For this purpose electrogravimetric techniques seem the best choice. During the last few years, the development of ac-electrogravimetry techniques (mass impedance) has allowed to identify in a fast way the participation of cations or anions during the electrochemical processes by only looking at the quadrant on which the impedance loop appears[32,4648]. Basically, a loop on the $1^{\text {st }}$ quadrant on the mass impedance plot indicates the participation of anions during electrochemical processes, but a loop on the $3^{\text {rd }}$ quadrant indicates the main participation of cations. We present in Figure 7 these acelectrogravimetry impedance plots at two potentials: $0.850 \mathrm{~V}$ and $0.975 \mathrm{~V}$ against the $\mathrm{Ag} / \mathrm{AgCl} / \mathrm{KCl}$ (sat). At $0.850 \mathrm{~V}$ the impedance loop appears on the $3^{\text {rd }}$ quadrant, confirming the main participation of potassium at these potentials, and at $0.975 \mathrm{~V}$, where we propose a partial participation of anions, the mass impedance loop appears on the $1^{\text {st }}$ quadrant corroborating our hypothesis. The size of this last loop proves very small if compared with the $0.850 \mathrm{~V}$, indicating that both, cations and anions may participate at these potentials, and thus, the global mass signal appears to be smaller.

\section{Conclusion.}

Voltammetric peaks associated to the $P B \square P Y$ processes have been historically described as only one electrochemical process. However, results here presented corroborated that at least 3 different processes should be considered. One of

these processes corresponds to the oxidation of $\mathrm{Fe}_{\text {low spin }}^{2+}-\mathrm{CN}-\mathrm{Fe}_{\text {high spin }}^{3+}$ units and causes an increase in the absorbance at $430 \mathrm{~nm}$ (yellow) and a decrease at $690 \mathrm{~nm}$ (blue). This process has been described by the main participation of cations as counterions. The second process corresponds to the oxidation of these same centers, but the participation of anions as counterions is required since there are not enough cations within the s-PB film to balance the electrical charge. This second process is also related with changes of absorbance at $690 \mathrm{~nm}$ and changes of absorbance to a lesser extent at $430 \mathrm{~nm}$ and also at $900 \mathrm{~nm}$. The third process is related to the oxidation of 
$F e_{\text {low spin }}^{3+}-C N-F e_{\text {high spin }}^{2+}$ which corresponds to trapped iron sites and causes absorbance changes at other different wavelengths $900-1000 \mathrm{~nm}$.

These hypotheses here proposed allow explaining several experimental observations concerning the electrochemical behavior of PB films. One of them is the non-stability of i-PB films against successive cycling around the $P B \square \quad P Y$ since there is no cation within the film and the balance of the electrical charge causes the collapse of the crystal structure. After conversion to the s-PB, the presence of potassium cations within the film makes possible that the oxidation process takes place in a reversible way, however the electrical charge enclosed in the $P B \square P Y$ voltammogram proves clearly smaller than the electrical charge enclosed in the $P B \square E S$ since the s-PB structure only contains $3 \mathrm{Fe}^{2+}$ sites by each $4 \mathrm{Fe}^{3+}$ sites. Besides there is only $2 \mathrm{~K}^{+}$ cations by each $3 \mathrm{Fe}^{2+}$, then not all $\mathrm{Fe}^{2+}$ oxidized may be balanced by expelling potassium cations and some chloride anions should be included. This fact causes two different $\mathrm{Fe}^{2+}$ sites within the structure. The electrochemical processes associated to these centers take place at slightly different potentials and cause changes of absorbance at $690 \mathrm{~nm}$ and $430 \mathrm{~nm}$ mainly. A third process has been identified and associated to the presence of some ionic trapped sites within the s-PB structrure. Redox processes of these trapped sites take place at more anodic potentials and cause changes of absorbance at $900 \mathrm{~nm}$.

\section{Acknowledgements}

Part of this work was supported by CICyT project CTQ2011-28973/BQU. J. A. acknowledges his position to the Ajuntament de València.

\section{REFERENCES}

[1] R.J. Mortimer, D.R. Rosseinsky, J. Chem. Soc.-Dalton Trans. (1984) 2059.

[2] D. Ellis, M. Eckhoff, V.D. Neff, J. Phys. Chem. 85 (1981) 1225.

[3] K. Itaya, K. Shibayama, H. Akahoshi, S. Toshima, J. Appl. Phys. 53 (1982) 804.

[4] P.R. Bueno, D. Gimenez-Romero, C. Gabrielli, J.J. Garcia-Jareno, H. Perrot, F. Vicente, J. Am. Chem. Soc. 128 (2006) 17146.

[5] D. Gimenez-Romero, J. Agrisuelas, J.J. Garcia-Jareno, J. Gregori, C. Gabrielli, H. Perrot, F. Vicente, J. Am. Chem. Soc. 129 (2007) 7121. 
[6] D. Gimenez-Romero, J.J. García-Jareño, J. Agrisuelas, F. Vicente, J. Phys. Chem. C 112 (2008) 20099.

[7] K. Derwinska, K. Miecznikowski, R. Koncki, P. Kulesza, S. Glab, M. Malik, Electroanalysis. 15 (2003) 1843.

[8] J. Li, J.D. Qiu, J.J. Xu, H.Y. Chen, X.H. Xia, Adv. Funct. Mater. 17 (2007) 1574.

[9] A. Ernst, O. Makowski, B. Kowalewska, K. Miecznikowski, P. Kulesza, Bioelectrochem. 71 (2007) 23.

[10] V.D. Neff, J. Electrochem. Soc. 125 (1978) 886.

[11] K. Itaya, H. Akahoshi, S. Toshima, J. Electrochem. Soc. 129 (1982) 1498.

[12] K. Itaya, T. Ataka, S. Toshima, J. Am. Chem. Soc. 104 (1982) 4767.

[13] K. Itaya, T. Ataka, S. Toshima, J. Am. Chem. Soc. 104 (1982) 3751.

[14] K. Itaya, T. Ataka, S. Toshima, T. Shinohara, J. Phys. Chem. 86 (1982) 2415.

[15] J.F. Keggin, F.D. Miles, Nature 137 (1936) 577.

[16] C.A. Lundgren, R.W. Murray, Inorg. Chem. 27 (1988) 933.

[17] P.R. Bueno, F.F. Ferreira, D. Gimenez-Romero, G.O. Setti, R.C. Faria, C. Gabrielli, H. Perrot, J.J. Garcia-Jareno, F. Vicente, J. Phys. Chem. C 112 (2008) 13264.

[18] F.F. Ferreira, P.R. Bueno, G.O. Setti, D. Gimenez-Romero, J.J. Garcia-Jareno, F. Vicente, Appl. Phys. Lett. 92 (2008).

[19] H.J. Buser, D. Schwarzenbach, W. Petter, A. Ludi, Inorg Chem 16 (1977) 2704.

[20] F. Felix, A. Ludi, Inorg. Chem. 17 (1978) 1782.

[21] P. Day, F. Herren, A. Ludi, H.U. Gudel, F. Hulliger, D. Givord, Helv. Chim. Acta 63 (1980) 148.

[22] F. Herren, P. Fischer, A. Ludi, W. Halg, Inorg. Chem. 19 (1980) 956.

[23] J. Agrisuelas, J.J. García-Jareño, F. Vicente, J Phys Chem C 116 (2012) 1935.

[24] P.R. Bueno, D. Giménez-Romero, F.F. Ferreira, G.O. Setti, J.J. Garcia-Jareño, J. Agrisuelas, F. Vicente, J. Phys. Chem. C 113 (2009) 9916.

[25] A. Roig, J. Navarro, J.J. Garcia, F. Vicente, Electrochim. Acta 39 (1994) 437.

[26] A. Roig, J. Navarro, R. Tamarit, F. Vicente, J. Electroanal. Chem. 360 (1993) 55.

[27] J.J. GarciaJareno, J. NavarroLaboulais, F. Vicente, Electrochim Acta 41 (1996) 2675.

[28] J. Agrisuelas, C. Gabrielli, J.J. Garcia-Jareno, D. Gimenez-Romero, J. Gregori, H. Perrot, F. Vicente, J Electrochem Soc 154 (2007) F134.

[29] A. Hamnett, S. Higgins, R. Mortimer, D. Rosseinsky, J. Electroanal. Chem. 255 (1988) 315.

[30] B.J. Feldman, O.R. Melroy, J. Electroanal. Chem. 234 (1987) 213.

[31] P.A. Christensen, A. Hamnett, S.J. Higgins, J. Chem. Soc. Dalton Trans. (1990) 2233.

[32] J.J. García-Jareño, A. Sanmatías, F. Vicente, C. Gabrielli, M. Keddam, H. Perrot, Electrochim. Acta 45 (2000) 3765.

[33] A. Roig, J. Navarro, R. Tamarit, F. Vicente, J. Electroanal. Chem. 360 (1993) 55.

[34] J. Agrisuelas, P.R. Bueno, F.F. Ferreira, C. Gabrielli, J.J. Garcia-Jareno, D. Gimenez-Romero, H. Perrot, F. Vicente, J. Electrochem. Soc. 156 (2009) P74.

[35] J. Agrisuelas, D. Giménez-Romero, J.J. García-Jareño, F. Vicente, Electrochem. Commun. 8 (2006) 549.

[36] J.J. García-Jareño, J. Navarro-Laboulais, A. Sanmatías, F. Vicente, Electrochim. Acta 43 (1998) 1045.

[37] D. Benito, J.J. García-Jareño, J. Navarro-Laboulais, F. Vicente, J. Electroanal. Chem. 446 (1998) 47. 
[38] J.J. García-Jareño, J. Navarro-Laboulais, F. Vicente, Electrochim. Acta 42 (1997) 1473.

[39] C. Lamy, C. Herrmann, J. Electroanal. Chem. 59 (1975) 113.

[40] D. Garreau, P. Hapiot, J. Saveant, J. Electroanal. Chem. 281 (1990) 73.

[41] J.J. García-Jareño, C. Gabrielli, H. Perrot, Electrochem. Commun. 2 (2000) 195.

[42] J. Agrisuelas, J.J. García-Jareño, D. Gimenez-Romero, F. Vicente, J. Phys. Chem. C 113 (2009) 8438.

[43] M.B. Robin, Inorg. Chem. 1 (1962) 337.

[44] A.J. Bard, L.R. Faulkner, Electrochemical Methods: Fundamentals and Applications, 2nd ed., Wiley, 2000.

[45] J. Agrisuelas, J. Garcia-Jareno, D. Gimenez-Romero, F. Vicente, Electrochim. Acta 55 (2010) 6128.

[46] C. Gabrielli, M. Keddam, N. Nadi, H. Perrot, in:, Work. Electrochem. Electroact. Polym. Films Weepf97, Dourdan, France, 1997, pp. 2095-2103.

[47] C. Gabrielli, J.J. Garcia-Jareno, M. Keddam, H. Perrot, F. Vicente, J. Phys. Chem. B 106 (2002) 3182.

[48] J. Agrisuelas, J.J. García-Jareño, D. Gimenez-Romero, F. Vicente, J. Phys. Chem. C 113 (2009) 8430. 
Table 1. Parameters obtained from the fitting of experimental voltammetric curves and absorbance derivative curves to equations (10) and (12) respectively.

\begin{tabular}{|c|c|c|c|c|c|c|c|}
\hline Parameter & $\mathrm{C}_{1}$ & $b_{1}$ & $\mathbf{E}_{1}^{0}$ & $\mathrm{C}_{2}$ & $\mathbf{b}_{2}$ & $\mathbf{E}_{2}^{0}$ & $\mathrm{C}_{2} / \mathrm{C}_{1}$ \\
\hline & A or a.u. $\mathrm{s}^{-1}$ & $\mathrm{~V}^{-1}$ & V & A or a.u. $\mathrm{s}^{-1}$ & $\mathrm{~V}^{-1}$ & V & \\
\hline i (c) & 0.00005 & 26 & 0.941 & 0.00002 & 18 & 1.037 & 0.40 \\
\hline $\mathrm{dA}^{430} / \mathrm{dt}(\mathrm{c})$ & 0.0021 & 21 & 0.944 & 0.00052 & 13 & 1.010 & 0.25 \\
\hline $\mathrm{dA}^{690} / \mathrm{dt}(\mathrm{c})$ & -0.0070 & 24 & 0.948 & -0.0029 & 16 & 1.047 & 0.41 \\
\hline $\mathrm{dA}^{900} / \mathrm{dt}(\mathrm{c})$ & -0.0014 & 24 & 0.989 & -0.0019 & 38 & 1.060 & 1.36 \\
\hline i (a) & -0.00006 & 25 & 0.906 & -0.00004 & 12 & 0.989 & 0.67 \\
\hline $\mathrm{dA}^{430} / \mathrm{dt}(\mathrm{a})$ & -0.0023 & 25 & 0.900 & -0.00072 & 17 & 0.980 & 0.31 \\
\hline $\mathrm{dA}^{690} / \mathrm{dt}$ (a) & 0.0062 & 29 & 0.901 & 0.0037 & 14 & 0.989 & 0.60 \\
\hline$d A^{900} / d t(a)$ & 0.0014 & 21 & 0.970 & 0.0014 & 48 & 1.040 & 1.00 \\
\hline
\end{tabular}


Figure LEGENDS

Figure 1. 3D plot of absorbance derivative changes during a voltammetrix scan from $0.2 \mathrm{~V}$ to $1.2 \mathrm{~V}$ against the $\mathrm{Ag} / \mathrm{AgCl} / \mathrm{KCl}$ (sat) reference electrode for a s-PB film /ITO electrode in a $\mathrm{KCl} 0.5 \mathrm{M}, \mathrm{pH}=3.0$ solution. Scan rate : $20 \mathrm{mV} \mathrm{s}^{-1}$.

Figure 2.Absorbance derivative changes at $430 \mathrm{~nm}, 690 \mathrm{~nm}$ and $900 \mathrm{~nm}$ during a voltammogram of a s-PB film /ITO electrode in a $\mathrm{KCl} 0.5 \mathrm{M}, \mathrm{pH}=3.0$ solution. Scan rate $: 5 \mathrm{mV} \mathrm{s}^{-1}$.

Figure 3.Deconvolution of voltammetric peaks for the $P B \square \quad P Y$ process. 3a) corresponds to the cathodic scan and $3 \mathrm{~b}$ ) to the anodic scan. Filled squares are experimental data, discontinuous lines correspond to the partial contributions and continuous line the sum of both partial contributions. Experimental conditions: s-PB film /ITO electrode in a $\mathrm{KCl} 0.5 \mathrm{M}, \mathrm{pH}=3.0$ solution. Scan rate $: 5 \mathrm{mV} \mathrm{s}^{-1}$.

Figure 4.Deconvolution of absorbance derivative peaks at $430 \mathrm{~nm}$ during the $P B \square P Y$ process. $4 \mathrm{a}$ ) corresponds to the cathodic scan and $4 \mathrm{~b}$ ) to the anodic scan. Filled squares are experimental data, discontinuous lines correspond to the partial contributions and continuous line the sum of both partial contributions. Experimental conditions: s-PB film /ITO electrode in a $\mathrm{KCl} 0.5 \mathrm{M}, \mathrm{pH}=3.0$ solution. Scan rate : $5 \mathrm{mV}$ $\mathrm{s}^{-1}$.

Figure 5.Deconvolution of absorbance derivative peaks at $690 \mathrm{~nm}$ during the $P B \square \quad P Y$ process. 5a) corresponds to the cathodic scan and 5b) to the anodic scan. Filled squares are experimental data, discontinuous lines correspond to the partial contributions and continuous line the sum of both partial contributions. Experimental conditions: s-PB film /ITO electrode in a $\mathrm{KCl} 0.5 \mathrm{M}, \mathrm{pH}=3.0$ solution. Scan rate : $5 \mathrm{mV}$ $\mathrm{s}^{-1}$.

Figure 6.Deconvolution of absorbance derivative peaks at $900 \mathrm{~nm}$ during the $P B \square \quad P Y$ process. 6a) corresponds to the cathodic scan and $6 \mathrm{~b}$ ) to the anodic scan. Filled squares are experimental data, discontinuous lines correspond to the partial contributions and continuous line the sum of both partial contributions. Experimental conditions: s-PB film /ITO electrode in a $\mathrm{KCl} 0.5 \mathrm{M}, \mathrm{pH}=3.0$ solution. Scan rate : $5 \mathrm{mV}$ $\mathrm{s}^{-1}$.

Figure 7. ac-electrogravimetry of PB films on gold/quartz-crystal microbalance electrodes. Filled squares correspond to the $0.850 \mathrm{~V}$ potential and open circles to the $0.975 \mathrm{~V}$ potentials against the $\mathrm{Ag} / \mathrm{AgCl} / \mathrm{KCl}$ (sat) reference electrode. Solution was 0.5 $\mathrm{M} \mathrm{KNO}_{3}$ and $\mathrm{pH}=3.0$. 
Agrisuelas et al. 
Identification of electroactive sites in Prussian Yellow films.

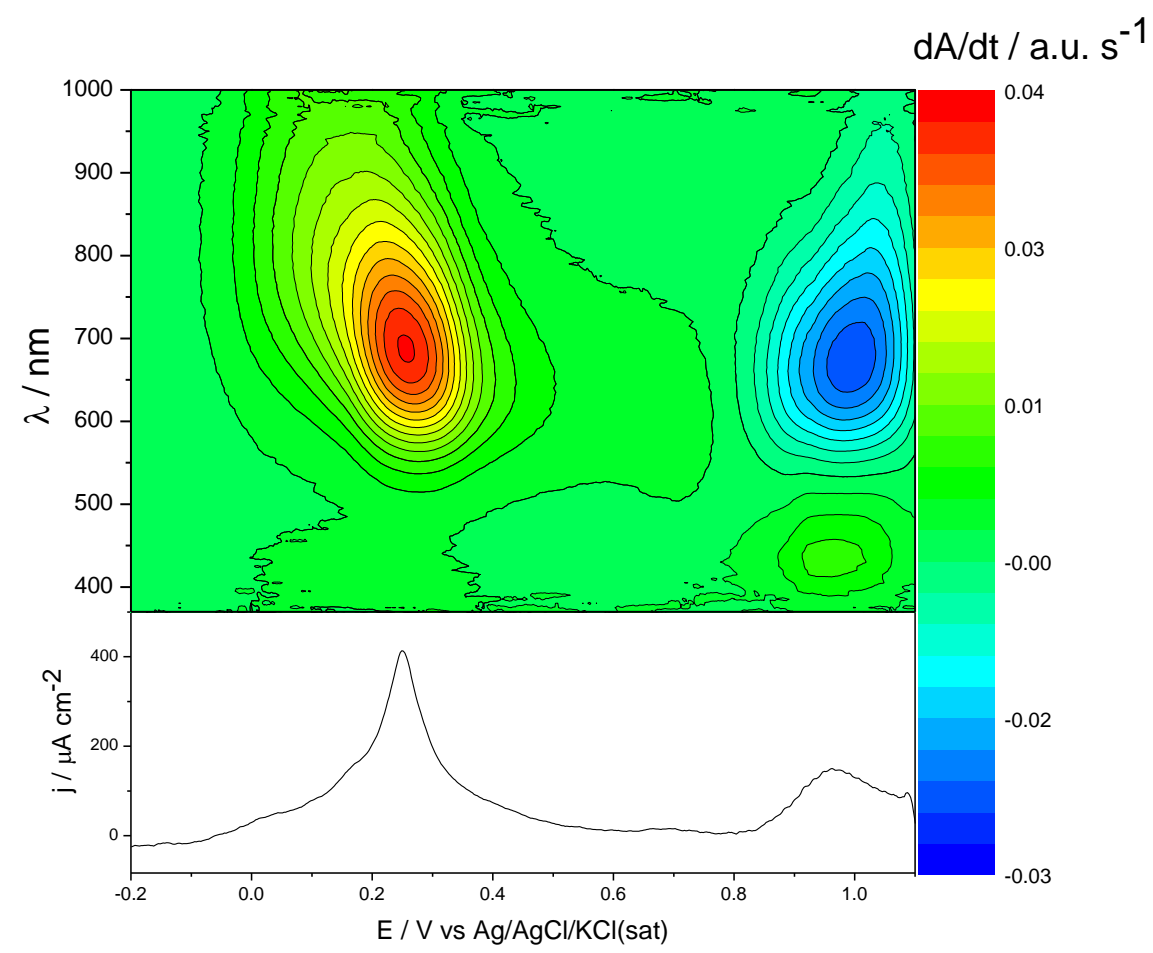

Figure 1. 


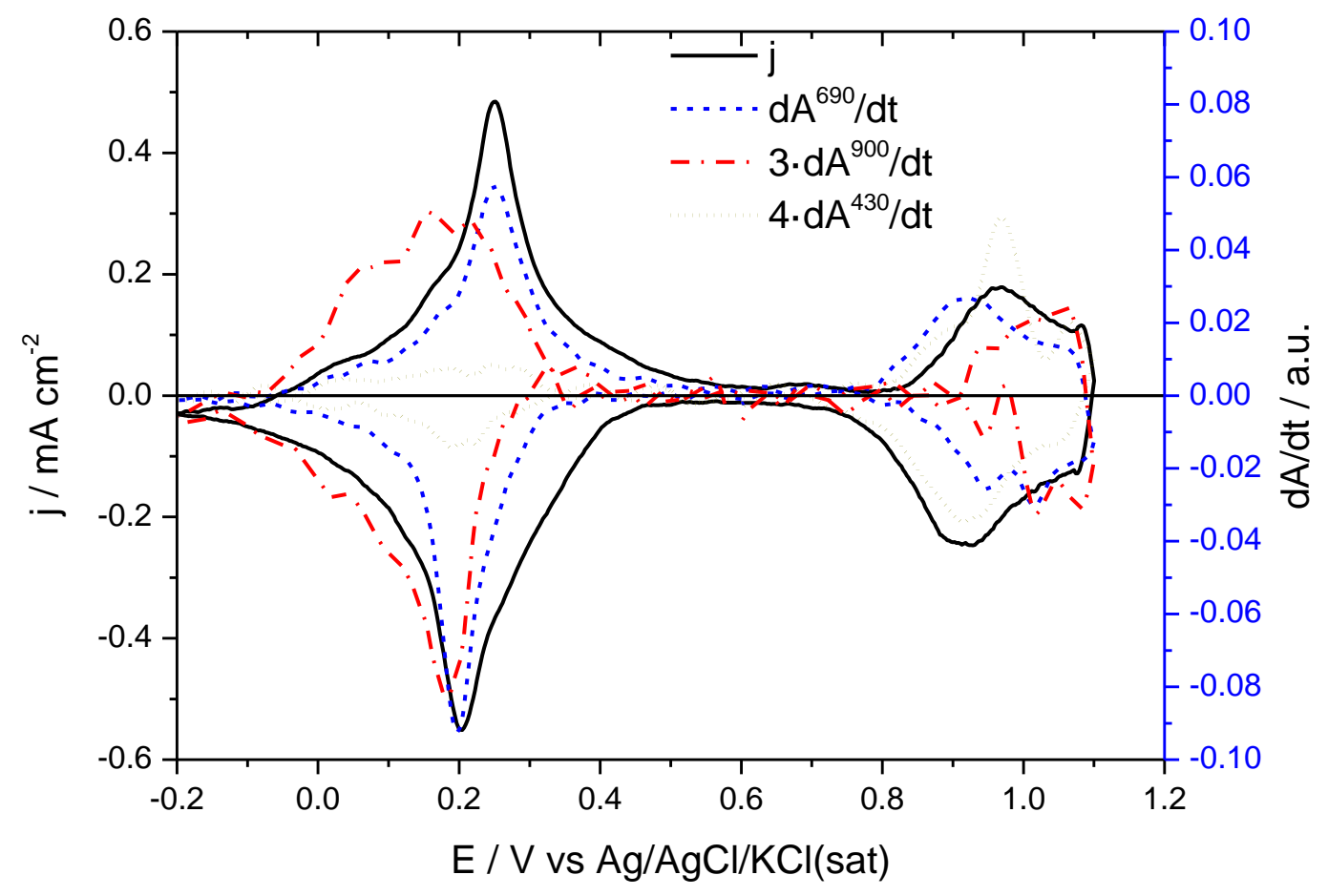

Figure 2. 
Identification of electroactive sites in Prussian Yellow films.

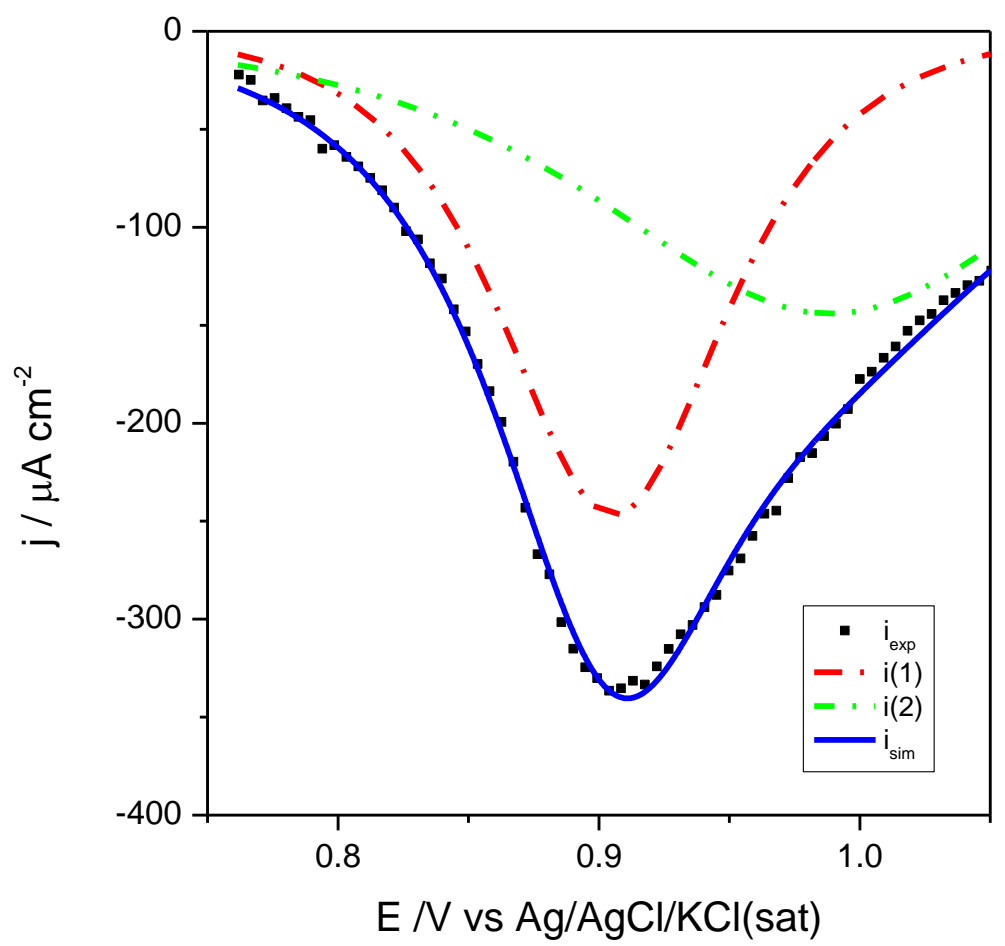

Figure 3a. 


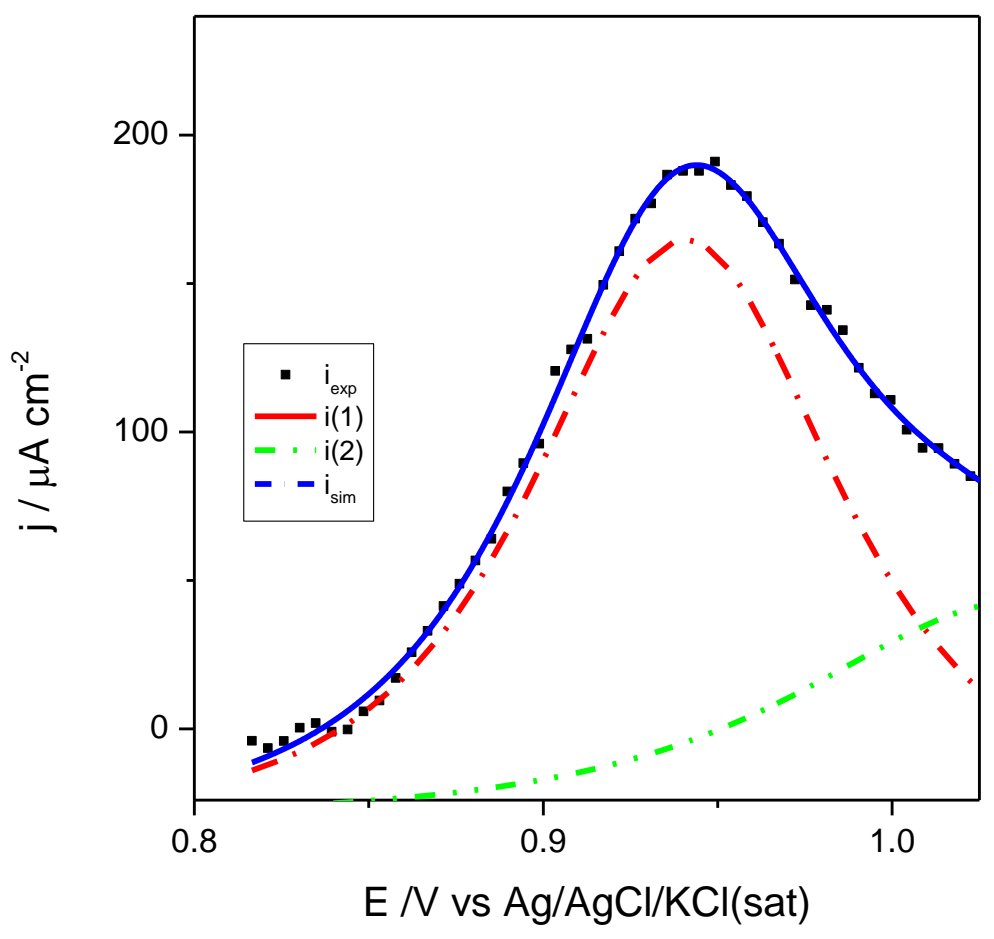

Figure $3 b$. 
Identification of electroactive sites in Prussian Yellow films.

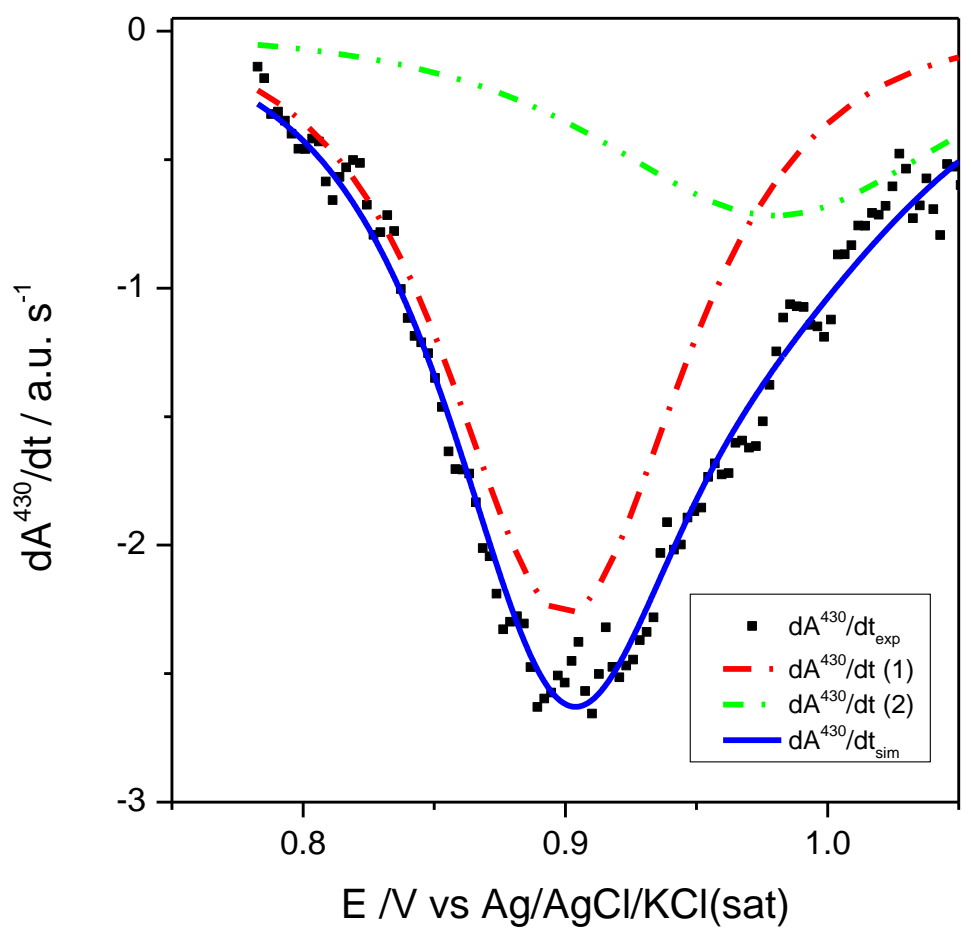

Figure 4a. 


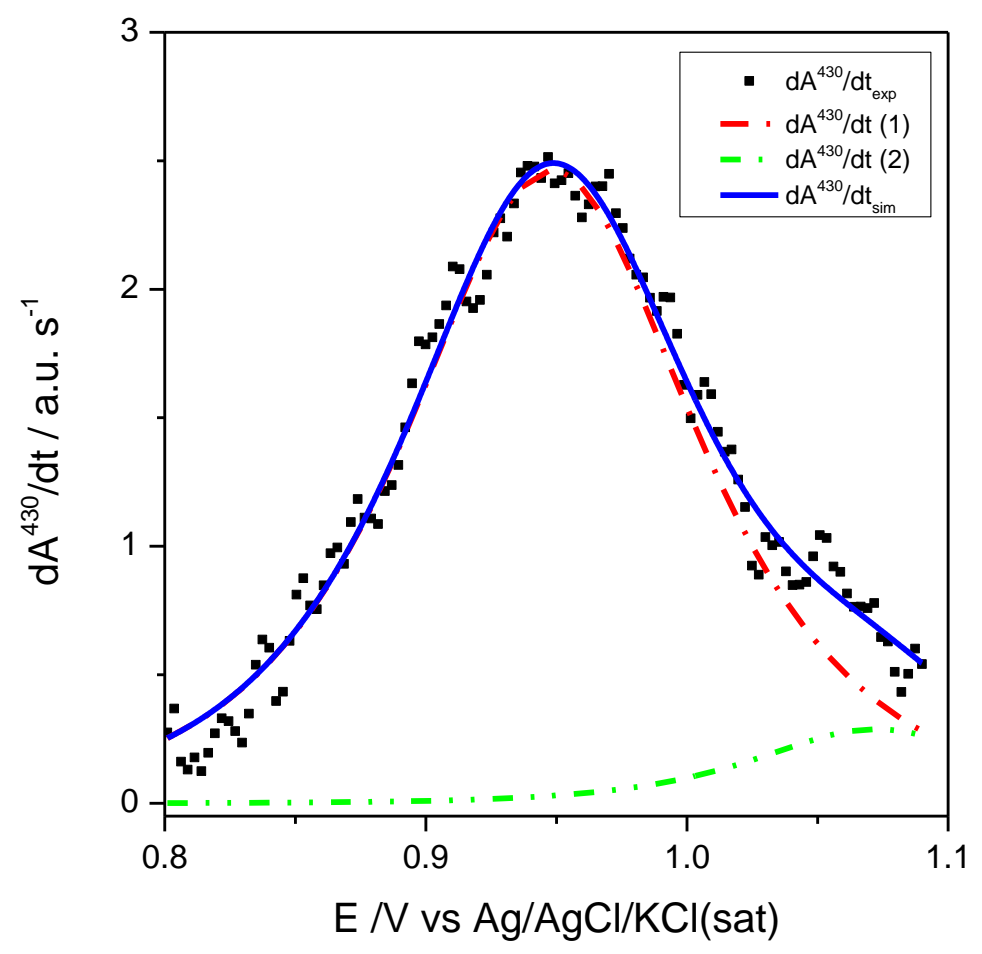

Figure 4b. 
Identification of electroactive sites in Prussian Yellow films.

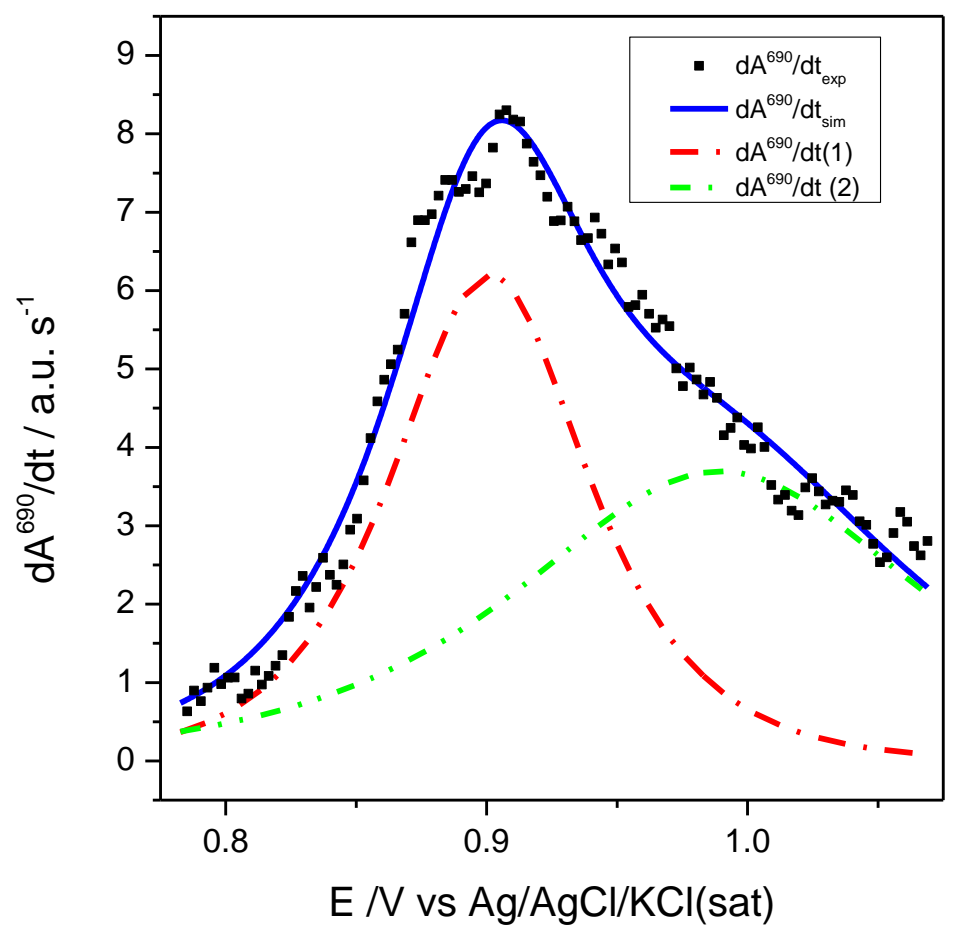

Figure $5 a$. 


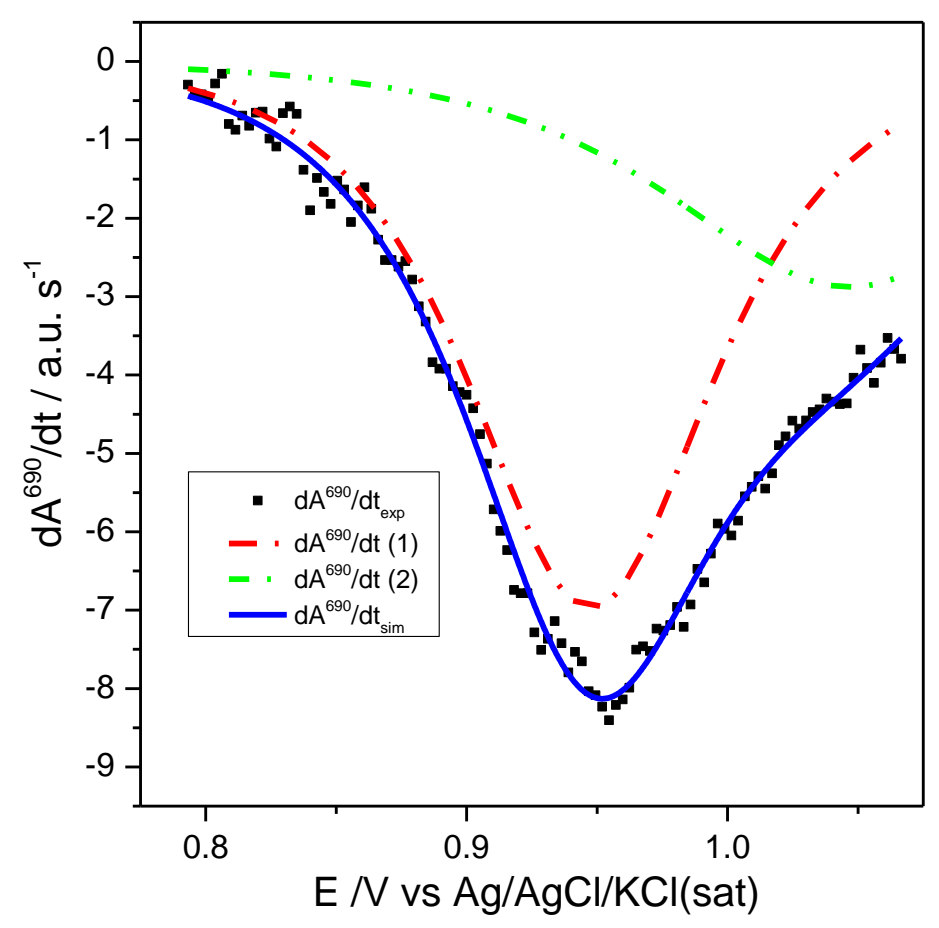

Figure 5b. 
Identification of electroactive sites in Prussian Yellow films.

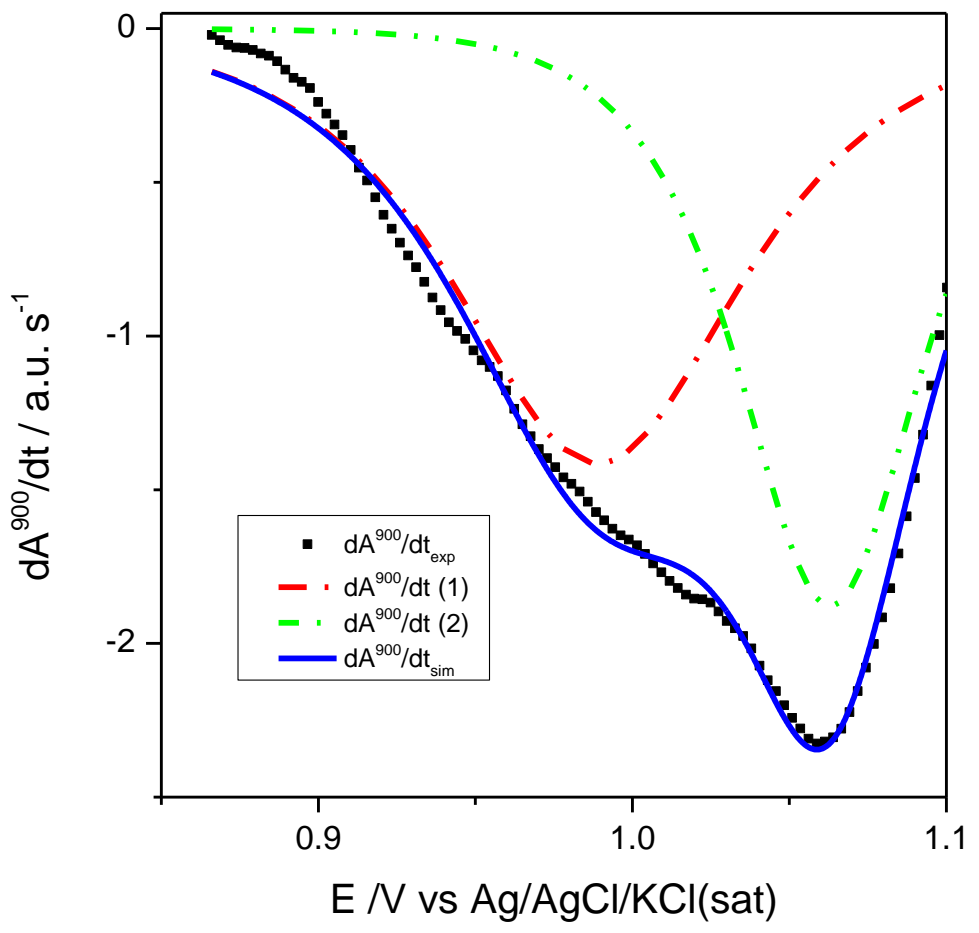

Figure 6a. 


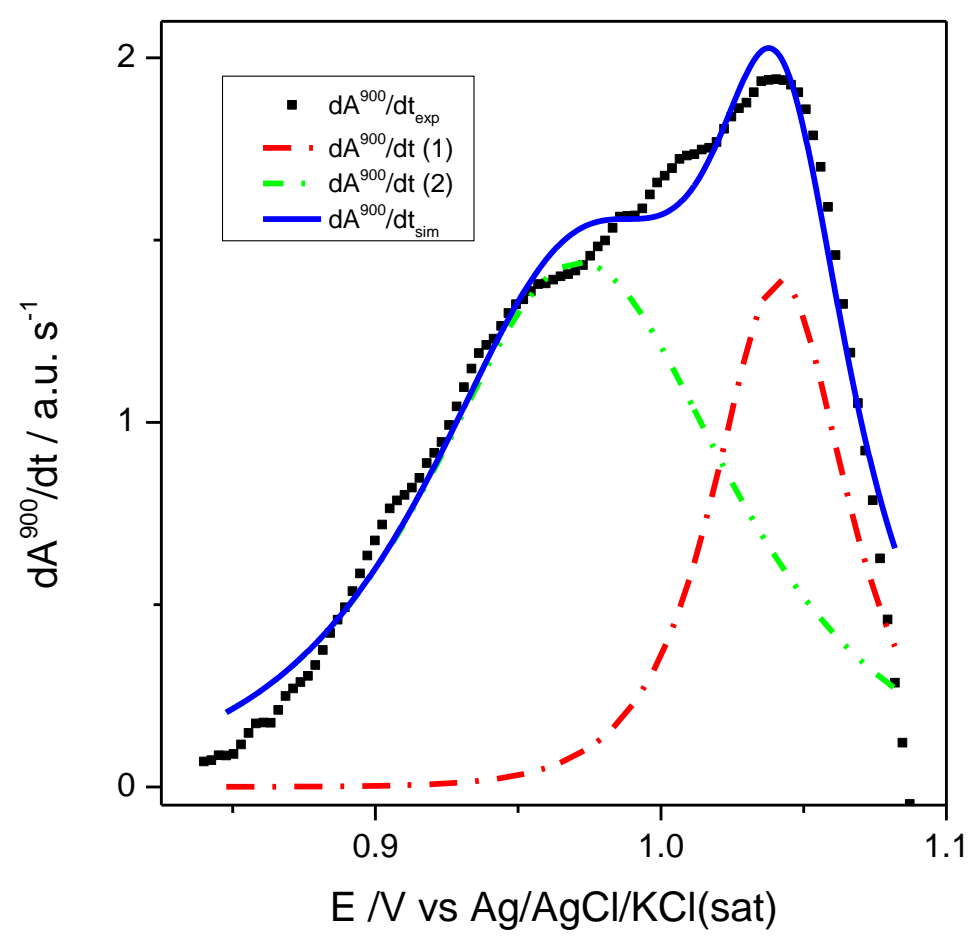

Figure 6b. 
Identification of electroactive sites in Prussian Yellow films.

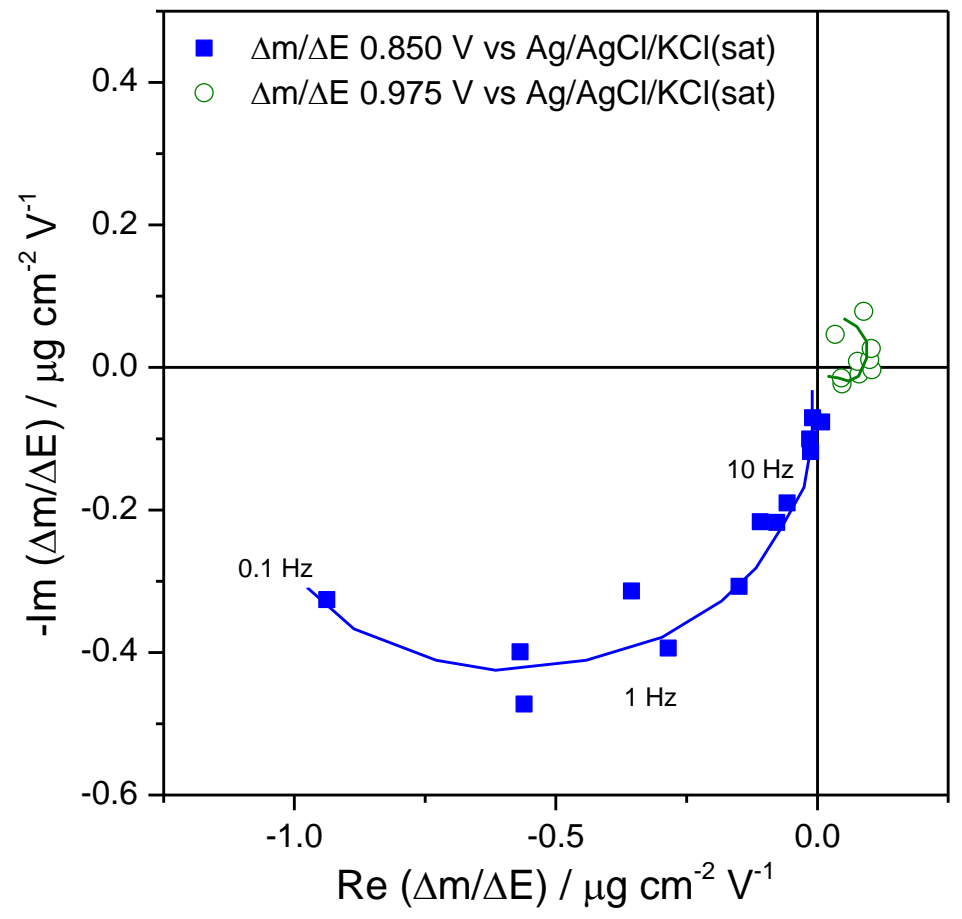

Figure 7. 